\title{
Guillain-Barré Variants as a Spectrum of Autoimmune Demyelinating Neuropathy
}

\author{
John Holton-Burke, Elizabeth M Aradine, Margaret Barton and Ahmad Bayrlee* \\ Department of Neurology, Virginia Commonwealth University Health System, USA
}

Submission: June 27, 2018; Published: July 05, 2018

*Corresponding author: Ahmad Bayrlee,Department of Neurology, Virginia Commonwealth University Health System,417 N 11th St, Richmond, VA 23298, USA, Tel: 804-828-9350; Fax: 804-828-9865; Email: ahmad.bayrlee@vcuhealth.org

Abstract

Background: Guillain-Barre Syndrome is a severe demyelinating polyneuropathy associated with multiple phenotypic variants including Miller-Fisher and Bickerstaff's Encephalitis. The aim of this article is to outline the clinical characteristics of these variants, as well as the utilization of diagnostic autoantibodies to determine clinical course, treatment and prognosis of those with GBS.

Methods: A comprehensive literature review regarding the concepts of acute inflammatory demyelinating polyneuropathy, Guillain-Barré syndrome. this included the diagnostic considerations, ganglioside components, EMG findings, treatment, and prognosis, as is currently discussed in pertinent journals. Here we summarize studies that have also analyzed Guillain-Barré syndrome from various perspectives and recognizes the need for further immunological investigation into autoimmune neurological diseases.

Results: In this case report and literature review we analyze the known autoimmune diseases affecting the central nervous system specifically the spectrum of demyelinating disease and inflammatory process of acute inflammatory demanding polyneuropathy also known Guillain-Barré syndrome. We discussed the early EMG, and radiological findings that can be present, as well as multiple variants their associated risk factors. In our literature review we do not find a more comprehensive review with relation to the current immunological investigation of inflammatory neurological diseases of the peripheral and central nervous system.

Conclusions: Although Guillain-Barré syndrome and its variants are self-limiting disease processes, the diagnosis is often difficult to make. To avoid a lengthy, costly, invasive work up, early recognition of cardinal signs and use of neuro-immunological tests to provide an early and more confident diagnosis.

Keywords: Guillain-Barré Syndrome; EMG; Prognosis; Education; Autoimmune diseases

\section{Introduction}

Guillain-Barré Syndrome (GBS) is a well-documented acquired immune mediated acute demyelinating neuropathy who's trademark clinical, electrophysiological, and pathological features of cerebrospinal fluid all assist in the diagnosis [1]. Clinical features required for diagnosis include progressive, typically ascending, limb weakness and eventual areflexia [1]; however, since the first documentation of GBS, variations to this presentation have been recognized. One GBS variant, Miller Fisher Syndrome (MFS), is characterized by ophthalmoplegia, ataxia, and areflexia[2]. It is associated with an antibody to GQ1b and positive serum titers are present in $85 \%$ of cases[3]. The GQ1b ganglioside is found on cranial nerves III, IV, and VI, among other neurological structures[4].In addition to the GQ1b antibody, other ganglioside antibodies have been associated with other variations of Guillain-Barre Syndrome, [5,6] providing further diagnostic value to the often-challenging cases of these variants. The ability to accurately identify GBS and its variants provides prognostic value to patients experiencing the acute and often debilitating neurological condition.

\section{Case Report}

A 45-year-old morbidly obese female with no significant past medical history presented to the emergency department with a two-day history of progressively worsening double vision, bilateral ptosis, and retro-orbital headache. She had been in her normal state of health with the notable exception of an upper respiratory infection and a persistent dry hacking cough that began approximately two weeks prior to presenting to the emergency department.The patient also noted a change in her voice, and difficulty swallowing solids, although she had attributed this to her viral illness. She was unable to focus on the computer screen at work due to the progressive double 
vision. Her visual disturbances were specifically described as horizontal double vision, with no change by near or distant vision. She otherwise denied any weakness, sensory changes, or unsteady gait.

Presenting physical examination was notable for multiple cranial nerve abnormalities. Her Pupils were dilated to $6 \mathrm{~mm}$ bilaterally and unreactive to light bilaterally. Extraocular movements revealed bilateral abduction and vertical gaze deficits. She also exhibited bilateral ptosis which was more severe on the left, as well as a faint left facial droop. Several hours after arrival, the patient rapidly deteriorated. She was noted to have a more dysphonic voice and complete eyelid paresis. She also developed a slight ataxic gait. Her muscle strength was preserved, and deep tendon reflexes remained intact throughout. Her mental status was not affected to the most part.

Admission Computerized tomography (CT) of the head revealed questionable hypodensity in the midbrain (which was read later by the radiologist as likely artifact). Computed tomography angiogram (CTA) of the head and neck was negative for any vascular abnormality. Unfortunately, due to the patients' large body habitus, she was unable to fit into the magnetic resonance imaging (MRI) machine. Repeat head CT at later time showed no changes compared to previous head CT.

The patient continued to show a decline in neurological and respiratory status which ultimately required intubation. Due to her rapid decline and deficits that localized to the brainstem, she underwent a significant workup investigating possible vascular etiologies, infectious etiologies as well as a possible acute demyelinating process. Treatment with intravenous immunoglobulin (IVIG) or plasma exchange was deferred initially secondary to the broad diagnostic possibilities. Conventional cerebral angiogram was pursued and it was negative for aneurysm, vasculitis changes or any other abnormality.

Cerebrospinal fluid(CSF) studies showed elevated IgG/Alb ratio to 0.28 (normal range $0.00-0.21$ ), normal glucose $50 \mathrm{mg}$ / $\mathrm{dl}$, normal protein $28 \mathrm{mg} / \mathrm{dl}$, and no pleocytosis.Electromyogram (EMG) and nerve conduction study(NCS) was performed which was normal but had limited interpretation due to ICU artifact. Preliminary laboratory investigation into myasthenia gravis, thyroid pathology, autoimmune, infectious, or metabolic etiologies were all negative.

She was treated with 5 days of intravenous immunoglobulin (IVIG). Due to prolonged intubation and inability to liberate from the ventilator, the patient underwent tracheostomy and percutaneous endoscopic gastrostomy (PEG) tube placement. Her symptoms minimally improved. She was offered plasma exchange; but she declined. At the end of her hospitalization, GQ1b antibody result returned positive. She declined placement to a skilled nursing facility and she was discharged to home with tracheostomy and PEG tube training.
At 1-month clinic follow up, her diet was advanced by speech therapy and she could tolerate soft foods. She still had unsteady gait and required the assistance of a rolling walker. Her diplopia and ptosis improved, but the slight left facial droop persisted.

At 3 months follow up, the patient was ambulating outside of the house without a rolling walker, she was advanced to a regular diet and she was working with general surgery for trach weaning. She no longer had diplopia but still had a slight left facial droop.

\section{Discussion}

Autoimmune diseases affecting the Central Nervous System are not uncommon, and disease pathology can represent a spectrum of demyelinating disease or inflammatory process. The traditional clinical diagnostic criteria for GBS includes progressive motor weakness of more than one limb with areflexia [1]. CSF will often show elevated protein after one week of symptoms [1], and electrodiagnostics studies will show nerve conduction slowing or complete conduction block in up to $80 \%$ of patients[1]. Not all nerves are affected, and the electromyography is often normal in the first few weeks of illness[1]. The combination of clinical, laboratory and electrodiagnostic criteria to diagnose GBS were established by both neurologists and non-neurologists to simplify the diagnosis; however, it has been discovered that multiple variations of GBS have now been described which do not meet the original criteria.

The most common form of Guillain-Barre syndrome is acute inflammatory demyelinating polyneuropathy (AIDP). AIDP comprises $80-90 \%$ of GBS and is characterized by progressive ascending paralysis, with selective leg weakness (56\%), arm and leg weakness (32\%), and arm weakness (12\%) [7-9]. A prodromal illness of upper respiratory infection or diarrhea, most commonly with campylobacter jejuni, is identified in 60$70 \%$ of cases $[7,9]$. Electromyography shows demyelination with or without axonal loss with reduced $\mathrm{H}$ reflex in $97 \%$ and $\mathrm{F}$ waves in $84 \%$ with increased. Demyelination features are present in at least two different nerves [9].

The second most common form of GBS is acute motor axonal neuropathy (AMAN) and represents $5-10 \%$ of GBS cases in the United States. AMAN is a rapidly progressive weakness of both upper and lower extremities, sparing the face, with a loss of reflexes[10]. Like AIDP, AMAN is typically preceded by a respiratory infection or campylobacter jejuni[5,11]. AMAN does not have sensory or peripheral nerve demyelination [12] and electrophysiology shows axonal degeneration with reduced or absent distal compound muscle action potentials [10]. Conduction block can also be seen on EMG which can show reversibility; however, without evidence of remyelination [10]. The associated ganglioside autoantibodies for AMAN are listed in Table 1. 
Table 1: GBS variants and associated antibodies.

\begin{tabular}{|c|c|}
\hline Antibodies & Syndromes \\
\hline GM-1 & Acute Motor Axonal Neuropathy (AMAN) [5] \\
\hline GD1a & AMAN, Bickerstaff's Encephalitis \\
\hline GD1b & AMAN, Pharyngeal-cervical-brachial weakness [6] \\
\hline GQ1b & $\begin{array}{l}\text { AIDP, Miller-Fisher, Bickerstaff's, Pharyngeal-cervical- } \\
\text { brachial weakness }\end{array}$ \\
\hline GT1a & Pharyngeal-cervical-brachial weakness \\
\hline
\end{tabular}

In addition to AMAN, acute sensorimotor axonal neuropathy (AMSAN) is also characterized by rapidly progressive weakness; however, AMSAN differs in that it also includesaxonal damage to the dorsal and ventral roots, causing prominent sensory manifestations $[13,8]$. Over the course of the disease, AMSAN can also involve small fibers causing burning pain and autonomic symptoms [14].

Miller Fisher syndrome (MFS), as mentioned briefly above, is a variant of GBS which is characterized by ophthalmoplegia, ataxia, and areflexia [2]. Descriptions of the syndrome were first published by Dr. Miller Fisher in NEJM in 1956 [15]. Patients can have severe ataxia with normal muscle strength. While areflexia is part of the triad, $43 \%$ of patients have normal reflexes [16]. Miller Fisher syndrome has more recently been associated with the anti-GQ1b antibodies and is positive in $85 \%$ of cases $[2,4]$. Bickerstaff encephalitis is similar to MFS with the exception of abnormal mental status examination and abnormal reflexes. Patients with this variant of GBS have hyperreflexia, rather than areflexia seen in MFS, and encephalopathy in addition to ophthalmoplegia and ataxia [17].Bickerstaff encephalitis, is also associated with the anti-GQ1b antibody [18].

Uncommon variants of GBS include acute pan-dysautonomia, pure sensory GBS, and acute bulbar palsy. Acute pandysautonomia is characterized by symptoms such as diarrhea, vomiting, dizziness, abdominal pain, orthostatic hypotension, urinary retention, pupillary abnormalities, variable heart rate and decreased sweating/salivation/lacrimation [19,20]. Reflexes are typically diminished or absent and patients can have variable sensory symptoms $[19,20]$. Acute pan-dysautonomia is a self-limiting disease process that completely resolves, the reason it is considered a variant of GBS [20]. Pan-dysautonomia is associated with antibodies to AChR and values greater than $1.00 \mathrm{nmol} / \mathrm{L}$ were present in $50 \%$ of cases [19]. Elevated titer levels after 1 month correlated with increased symptoms [19].

Pure sensory GBS is also known as sensory ataxic neuropathy in some literature [21]. Pure sensory GBS is characterized by sensory symptoms, ataxia, from involvement of the large sensory fibers, and areflexia [21-23]. Antibody to GD1b is present in $46 \%$ of pure sensory GBS [21]. Ophthalmoplegia is not present in pure sensory GBS; however, GQ1b antibody has been positive in $50 \%$ of patients [21]. Sensory nerve conduction studies show decreased to absent sensory potentials as early as 6 days from symptom onset [22-25]. Motor nerve conduction studies are normal [22-25]. Follow up sensory nerve conduction studies show improved amplitude and velocity at 3-6 months; however, not complete recovery [22-25]. Patients have complete to near complete resolution of sensory symptoms within 1-3 months; however, patients have persistent areflexia with or without mild ataxia [22-25].

The pharyngeal-cervical-brachial (PCB) variant of GuillainBarré syndrome is defined by rapidly progressive oropharyngeal and cervicobrachial weakness associated with areflexia in the upper limbs.Half of patients with PCB carry IgG anti-GT1a antibodies which often cross-react with GQ1b.

Our patient represented a combination of different GBS variants including MFS (ataxia and ophthalmoplegia), Bickerstaff encephalitis (normal to hyperreflexia), and pharyngeal- cervicalbrachial weakness (hoarseness and dysphagia). All of which share the same antibody (GQ1b). We can propose the term "AntiGQ1b syndrome" to describe such patients who do not fit under one diagnosis, but rather under the spectrum of this disease[26].

The differential diagnosis to Guillain-Barré Syndrome and its variants are broad and vary depending on the presentation of Guillain-Barré. These include vascular diseases such as brainstem stroke, infectious diseases, and chronic autoimmune diseases such as neuromyelitis optica, multiple sclerosis, myasthenia gravis, and neurosarcoidosis.

Table 2: Other Prominent Autoimmune Syndromes of the CNS.

\begin{tabular}{|c|c|c|}
\hline Example Antibodies & Syndromes & $\begin{array}{c}\text { Possible Disease } \\
\text { Associations }\end{array}$ \\
\hline $\begin{array}{c}\text { Nuclear and } \\
\text { Cytoplasmic Antigens } \\
\text { [30]: ANNA-1 (Hu), } \\
\text { ANNA-2 (Ri), ANNA- } \\
\text { 3, PCA-1 (Yo), Ma1, } \\
\text { Ma2 [30] }\end{array}$ & $\begin{array}{c}\text { Limbic Encephalitis, } \\
\text { Extra-limbic } \\
\text { encephalitis, Lambert } \\
\text { Eaton Syndrome, } \\
\text { peripheral } \\
\text { Neuropathies. }\end{array}$ & $\begin{array}{c}\text { Small Cell Carcinoma, } \\
\text { Thymoma, } \\
\text { Neuroblastoma, }\end{array}$ \\
\hline $\begin{array}{c}\text { Intracellular } \\
\text { Antigens:GAD-65, } \\
\text { Amphiphysin IgG }\end{array}$ & $\begin{array}{c}\text { Limbic Encephalitis, } \\
\text { Stiff Person } \\
\text { syndrome, seizures, } \\
\text { myelopathy, } \\
\text { Neuropathy }\end{array}$ & $\begin{array}{c}\text { Breast } \\
\text { adenocarcinoma, } \\
\text { Thymoma, Renal cell } \\
\text { adenocarcinoma, } \\
\text { small cell carcinoma }\end{array}$ \\
\hline $\begin{array}{c}\text { Surface Antigens: } \\
\text { NMDA, AMPA, } \\
\text { GABA, Voltage } \\
\text { gated Calcium and } \\
\text { Potassium channels } \\
\text { [32] }\end{array}$ & $\begin{array}{l}\text { Limbic Encephalitis, } \\
\text { Sleep disorders } \\
\text { (Insomnia, RBD), } \\
\text { Amnestic syndrome, } \\
\text { disinhibition. }\end{array}$ & $\begin{array}{l}\text { Hypothalmic tumor, } \\
\text { thymoma, ovarian } \\
\text { teratoma, lung } \\
\text { cancer (usually small } \\
\text { cell) }\end{array}$ \\
\hline
\end{tabular}

When considering other possible CNS involvement from autoimmune causes many other autoantibodies should be considered, and a wide variety of neurological disturbances including encephalopathy, sleep disorders, epilepsy and neuropathy can be included in the differential diagnosis [27]. These types of autoantibodies can be nuclear, cytoplasmic, intracellular, or surface antigens (Examples of which are noted in Table 2 [27-31]. The site of the antigen is not specific to the 


\section{Juniper Online Journal of Case Studies}

clinical syndrome, and a wide spectrum of disease can be noted with a singular autoantibody, whether this was produced by a secreting tumor, or idiopathically. Similarly, you can surmise that Gq1b autoantibodies will also have a spectrum of disease rather than multiple discrete entities.

\section{Conclusion}

Although Guillain-Barré syndrome and its variants are self-limiting disease processes, the diagnosis is often difficult to make. Often times the patient will undergo a lengthy, costly, invasive and anxiety provoking work up, such as in our patient's case. Early recognition of these self-limiting diseases not only decrease healthcare cost, but also gives patient reassurance. Given the challenge of diagnosing variants of GBS, the presence of antibodies specific to a variant can provide earlier and more confident diagnosis. This case report illustrates that autoimmune demyelinating disease that has been classified under the umbrella term Guillain-Barré variants, with different phenotypical presentations for multiple syndromes.

\section{References}

1. Asbury A (1981) Diagnostic considerations in Guillain-barré syndrome. Ann Neurol 9 Suppl: S1-S5.

2. Teener JW (2012) Miller Fisher's Syndrome. Simin Neurol 32(5): 512516.

3. Nishimoto Y, Odaka M, Hirata K, Yuki N (2004) Usefulness of anti-GQ1b IgG antibody testing in Fisher syndrome compared with cerebrospinal fluid examination. J Neuroimmunol 148(1-2): 200-205.

4. Chiba A, Kusunoki S, Obata H, Machinami R, Kanazawa I (1997) Ganglioside composition of the human cranial nerves, with special reference to pathophysiology of Miller Fisher syndrome. Brain Res 745(1-2): 32-36.

5. Yuki N, Susuki K, Koga M, Nishimoto Y, Odaka M, et al. (2004) Carbohydrate mimicry between human ganglioside GM1 and Campylobacter jejuni lipooligosaccharide causes Guillain-Barré syndrome. Proc Natl Acad Sci USA 101(31): 11404-11409.

6. Nagashima T, Koga M, Odaka M, Hirata K, Yuki N (2007) Continuous spectrum of pharyngeal-cervical-brachial variant of Guillain-Barre syndrome. Arch Neurol 64(10): 1519-1523.

7. Shah DN (2010) The Spectrum of Guillain-Barré Syndrome. Dis Mon 56(5): 262-265

8. Dimachkie MM, Barohn RJ (2013) Guillain-Barré Syndrome and Variants. Neurologic Clinics 31(2): 491-510.

9. Gordon PH, Wilbourn AJ (2001) Early electrodiagnostic findings in Guillain-barré syndrome. Arch Neurol 58(6): 913-917.

10. Kokubun N, Nishibayashi M, Uncini A, Odaka M, Hirata K, et al. (2010) Conduction block in acute motor axonal neuropathy. Brain 133(10): 2897-2908.

11. Ho TW, Mishu B, Li CY, Gao CY, Cornblath DR, et al. (1995) GuillainBarré syndrome in northern China: relationship to Campylobacter jejuni infection and anti-glycolipid antibodies. Brain 118 (Pt 3): 597 605

12. McKhann GM, Cornblath DR, Griffin JW, Ho TW, Li CY, et al. (1993) Acute motor axonal neuropathy: a frequent cause of acute flaccid paralysis in China. Ann Neurol 33(4): 333-342.

13. Arcila-Londono X, Lewis RA (2012) Guillain-Barré syndrome. Semin Neurol 32(3): 179-186.
14. Kelkar P, McDermott WR, Parry GJ (2002) Sensory-predominant, painful, idiopathic neuropathy: inflammatory changes in sural nerves. Muscle Nerve 26(3): 413-416.

15. Fisher M (1956) An unusual variant of acute idiopathic polyneuritis (syndrome of ophthalmoplegia, ataxia, areflexia). N Engl J Med 255(2): $57-65$

16. Yuki N, Odaka M, Hirata K (2001) Acute ophthalmoparesis (without ataxia) associated with anti GQ1b IgG antibody: Clinical features. Ophthalmology 108(1): 196-200.

17. Odaka M, Yuki N, Yamada M, Koga M, Takemi T, etal. (2003) Bickerstaff's brainstem encephalitis: clinical features of 62 cases and a subgroup associated with Guillain-Barré syndrome. Brain 126(Pt 10): 22792290.

18. Overell JR, Hsieh ST, Odaka M, Yuki N, Willison HJ (2007) Treatment for Fisher syndrome, Bickerstaff's brainstem encephalitis and related disorders. Cochrane Database Syst Rev (1): CD004761.

19. Klein CM, Vernino S, Lennon VA, Sandroni P, Fealey RD, et al. (2003) The spectrum of autoimmune autonomic neuropathies. Ann of Neur 53(6): 752-758.

20. Young RR, Asbury AK, Corbet JL, Adams RD (1975) Pure PanDysautonomia with Recovery, Description and Discussion of Diagnostic Criteria. Brain 98(4): 613-636.

21. Ito M, Matsuno K, Sakumoto Y, Hirata K, Yuki N (2011) Ataxic Guillain-Barre syndrome and acute sensory ataxic neuropathy form a continuous spectrum. J Neurol Neurosurg Psychiatry 82(3): 294-299.

22. Miralles F, Montero J, Rene R, Martinez Matos JA (1992) Pure sensory Guillain-Barre syndrome. J Neurol Neurosurg Psychiatry 55(5): 411412.

23. Yang JJ, Huan MM, Jiang HJ, Song CL, Zhong L, et al. (2014) Pure sensory Guillain-Barre syndrome: A case report and review of the literature. Exp Ther Med 8(5): 1397-1401.

24. Lee SS, Lee SH (2006) Does sensory Guillain-Barre syndrome exist without any abnormalities in motor nerve conduction? Neurology 66(6): 947-948.

25. Oh S, LaGanke C, Claussen GC (2001) Sensory Guillain-Barre Syndrome. Neurology 56(1): 82-86.

26. Matsuo M, Odaka M, Koga M, Tsuchiya K, Hamasaki Y (2004) Bickerstaff's brainstem encephalitis associated with IgM antibodies to GM1b and GalNAc-GD1a. Journal of the Neurological Sciences 217(2): 225-228.

27. Pittock SJ, Palace J (2016) Paraneoplastic and idiopathic autoimmune neurologic disorders: approach to diagnosis and treatment. Handb Clin Neurol 133:165-183.

28. Gultekin SH, Rosenfeld MR, Voltz R, Eichen J, Posner JB, et al (2000) Paraneoplastic limbic encephalitis: Neurological symptoms, immunological findings and tumour association in 50 patients. Brain 123(Pt 7): 1481-1494.

29. Pittock SJ, Lucchinetti CF, Lennon VA (2003) Anti-neuronal nuclear autoantibody type 2: paraneoplastic accompaniments. Ann Neurol 53(5): 580-587.

30. Pittock SJ, Yoshikawa H, Ahlskog JE, Tisch SH, Benarroch EE, et al (2006) Glutamic acid decarboxylase autoimmunity with brainstem, extrapyramidal, and spinal cord dysfunction. Mayo Clin Proc 81(9): 1207-1214.

31. Irani SR, Alexander S, Waters P, Kleopa KA, Pettingill P, et al. (2010) Antibodies to Kv1 potassium channel-complex proteins leucine-rich, glioma inactivated 1 protein and contactin-associated protein-2 in limbic encephalitis, Morvan's syndrome and acquired neuromyotonia. Brain 133(9): 2734-2748. 


\section{Your next submission with Juniper Publishers} will reach you the below assets

- Quality Editorial service

- Swift Peer Review

- Reprints availability

- E-prints Service

- Manuscript Podcast for convenient understanding

- Global attainment for your research

- Manuscript accessibility in different formats

( Pdf, E-pub, Full Text, Audio)

- Unceasing customer service

Track the below URL for one-step submission https://juniperpublishers.com/online-submission.php 